\title{
RECOLHA E TRANSCRIÇÃO DE CORPORA ORAIS
}

\author{
Tiago Freitas
}

Instituto de Linguística Teórica e Computacional (Portugal)

Põe a gramática em prática

Didáctico-dramaticamente

Citando técnicas poéticas

Com estéticas fonéticas

Sempre atento ao surpreendente

Com métricas à frente

Para mentes cépticas e exigentes!

Poetas de Karaoke, Sam the Kid (2006)

\section{INTRODUÇ̃̃O}

O texto em epígrafe corresponde à transcrição de um excerto de uma conhecida canção do repertório urbano moderno português. Fazendo uma rápida consulta à internet, perceberemos que nenhuma das transcrições da letra da música aí publicadas é idêntica à que foi aqui lavrada. Acharemos divergências não só no que diz respeito à translineação mas sobretudo no que concerne ao conteúdo verbal: aquilo que interpretei como um neológico advérbio de modo é transcrito das mais diversas maneiras, incluindo a plausível < didáctica ou dramaticamente> (o que nos conduziria à possibilidade, não atestada, de fazer a translineação antes da conjunção disjuntiva); a forma verbal que, à semelhança de outros, tomo por gerúndio encontra-se também exarada como o adjectivo de raro uso <citante>, aparecendo este no singular e no plural, ou mesmo como o desconhecido vocábulo <citanto>. A mesma plausibilidade do uso da conjunção disjuntiva encontramo-la naquilo que foi acima transcrito como o sexto verso: bem poderia ser <sempre atento ou surpreendente>, como escreveram vários transcritores. Descobriremos ainda considerável variação no que toca à ligação entre os dois ad- 
jectivos apresentados na última linha: para alguns trata-se de coordenação assindética, ao passo que outros discernirão, com dificuldade, um [i] distinto do [i] inicial de exigente. Isto para não falar na variação por que se caracteriza o uso de diacríticos e o emprego de grafias modificadas $<$ pa $>$ e $<$ p'ra $>$ representando a preposição para. Aprofundando a nossa consulta à internet, depressa concluiremos que esta inconstância na transcrição da letra dos Poetas de Karaoke não se cinge de modo nenhum ao excerto supracitado. Pelo contrário, existem passagens em relação às quais a oscilação se torna bem mais notória, facto a que não serão alheios os apreciáveis dotes de versificação do vocalista escutado.

Embora, nesta canção, o Sam the Kid enderece explicitamente os seus conselhos aos colegas de profissão, este texto poderia muito bem aplicar-se às pessoas que têm por ocupação executar transcrições do oral. E os problemas concretos que se põem à fixação da letra desta música popular, que poderão frustrar alguns admiradores do artista empenhados em repetir a sua cantiga, eventualmente num qualquer estabelecimento de karaoke, sentemnos os transcritores de fala espontânea a cada passo do seu trabalho. Mesmo com todas as comodidades permitidas pelas tecnologias actuais, a transcrição continua a ser apenas uma forma de interpretação muito imperfeita.

É, contudo, indiscutível que hoje em dia o trabalho de anotação de um corpus se encontra imensamente simplificado. O facto de o anotador poder reouvir os fragmentos em análise quantas vezes quiser, pela simples utilização de um rato de computador, sem ter, por exemplo, o desconforto de estar a rebobinar uma cassete continuamente, comporta vantagens consideráveis em termos de aceleração do ritmo de trabalho.

Mais relevante ainda é o facto de os modernos corpora serem já construídos de maneira a que o utilizador final possa, ele próprio, aceder aos dados sonoros e fazer as interpretações que mais se adequarem aos seus propósitos.

A par dessas facilidades, a era da informação em que vivemos veio também favorecer sobremaneira o processo de recolha de dados, multiplicando as fontes de onde é possível extrair fala de boa qualidade e permitindo reduzir consideravelmente o tempo que leva a constituir grandes bases de dados. Existe neste momento uma ubiquidade de recursos graváveis, nos meios de comunicação públicos e privados, uma inesgotável torrente de dados prontos a serem registados à qual o investigador do oral não pode ficar indiferente.

Por outro lado, o surgimento de iniciativas internacionais como o E-MELD e o IMDI, que disponibilizam documentos e ferramentas de análise de forma completamente aberta, veio tornar o complexo trabalho de construção das bases de dados cada vez mais acessível ao não-especialista. Com essas con- 
dições, a tarefa de edificar grandes corpora orais passou a estar ao alcance de qualquer um.

\section{PlanificaC̄̃̃O DO CORPUS}

Provavelmente o aspecto mais relevante a considerar aquando da planificação de um corpus de língua falada é o da utilidade que lhe pretendemos dar. Dependendo das necessidades de investigação e dos recursos disponíveis para a língua, poderemos optar por uma recolha de dados com fins específicos, por exemplo tendo em vista o aperfeiçoamento das ferramentas computacionais existentes ou com um âmbito mais abrangente. Dessa orientação inicial dependerão decisões importantes relacionadas com o desenho geral do corpus e o tipo de anotações a aplicar.

Nos últimos anos, temos vindo a assistir à emergência de corpora nacionais como o Corpus Gesproken Nederlans (CGN), construído como o equivalente do British National Corpus para a língua neerlandesa (Schuurman et al. 2004). Trata-se de projectos concebidos de raiz para a disponibilização de recursos para utilizações diversas, incluindo diferentes tipos de investigação linguística, didáctica da língua, tecnologia de fala, etc.

Corpora como o CGN, que compreende cerca de 900 horas de fala, implicam um considerável esforço financeiro e de recursos humanos e decorrem de um longo estádio de planeamento e organização inicial. Uma solução que pode abreviar e facilitar tal processo de preparação, e que também tem sido posta em prática recentemente, é a criação de projectos supranacionais tendo em vista a produção de corpora normalizados para várias línguas. Um caso desse tipo é o C-ORAL-ROM (Cresti et al. 2005), que resultou num corpus com 300 mil palavras do espanhol, francês, italiano e português (1,2 milhões palavras no total), totalizando cerca de 120 horas de transcrição. Foi um projecto desenvolvido com o objectivo específico de criar recursos representativos da fala espontânea de cada um dos idiomas, possibilitando a comparação directa de fenómenos linguísticos em diferentes tipos de discurso.

A planificação de um corpus de dimensão institucional está necessariamente condicionada ao programa de financiamento de que dispõe a instituição ou o conjunto de instituições envolvidas. A definição dos períodos de recolha e transcrição torna-se indispensável no caso de projectos a termo certo com limitado escopo temporal. Há que contar com os quase sempre inevitáveis cortes orçamentais aplicados sobre o plano inicial, que muitas vezes determinam a reestruturação completa dos objectivos da recolha. 
Além das implacáveis determinações de contenção financeira, os responsáveis pela planificação do corpus devem contar com atrasos decorrentes de problemas técnicos e de dificuldades na obtenção de gravações e autorizações pessoais, complicações que muitas vezes surgem a par da necessidade de desenvolver várias tarefas ao mesmo tempo. Uma solução para obviar alguns dos problemas que necessariamente sobrevêm nas fases de recolha e transcrição é a criação de um projecto-piloto de dez mil palavras (Schuurman et al. 2004). Desse modo, é possível também testar as regras e as ferramentas de transcrição a empregar, sendo possível antecipar muitas das contrariedades que surgem nesse âmbito.

\section{RECOLHA DO CORPUS}

Hoje em dia verifica-se uma tendência crescente para fazer recolhas de fala espontânea incluindo não só o áudio mas também o vídeo. O facto de ser escolhida a fala espontânea e não outros tipos de discurso decorre da necessidade desse tipo de dados que sentem, por exemplo, os investigadores que trabalham em aplicações computacionais (referidas por Rodríguez Banga e por García Mateo \& Cardenal López neste mesmo libro, e em Campbell 2004 e 2005, Shriberg 2005, inter al.), os que desenvolvem perspectivas téoricas ligadas à análise da conversação (Local \& Walker 2005, i.a.) e os que se ocupam de aplicações forenses (Rose 2002, i.a.). O facto de também ser recolhida a imagem decorre, por seu lado, da reconhecida importância que as pistas visuais assumem, por exemplo, na gestão do discurso (Barkhuysen et al. 2005, i.a.) e para a realização da proeminência (Beskow et al. 2006).

A opção pela recolha de ambos os tipos de sinal comporta, no entanto, cuidados e custos acrescidos, pelo que em alguns casos a representação em vídeo acaba por ser preterida, como aconteceu no projecto CORP-ORAL. A despeito desse facto, é um dado adquirido que os avanços tecnológicos havidos nas últimas décadas tornaram o equipamento de recolha mais acessível. A título de exemplo podemos pensar no caso dos gravadores digitais portáteis da marca japonesa Sony: o modelo de cassetes DAT D8 custava em 1997 cerca de 600 dólares americanos ao passo que o modelo de minidiscos MZ-RH1, que permite gravações em formato WAV de qualidade idêntica, mas oferecendo condições de autonomia e possibilidades de acesso e transferência de dados muito superiores (cf. Casey \& Gordon 2007 sobre as desvantagens da utilização a longo prazo do formato DAT), é vendido em 2007 por cerca de 300 dólares. O desenvolvimento do suporte digital, por outro lado, permite-nos hoje velocidades de acesso aos dados muito mais rápidas, 
soluções de armazenamento e organização dos arquivos mais eficazes e seguras e ainda a possibilidade de reprodução sem perda de qualidade e praticamente sem custos.

Independentemente de se avançar para a recolha de áudio e de vídeo ou só do primeiro, é importante tomar algumas decisões relativamente ao escopo e à quantidade de dados a recolher.

\subsection{Escopo}

O escopo da recolha determina os níveis de transcrição e etiquetagem adoptados no sistema de anotação do corpus, pelo que se torna conveniente ter uma ideia prévia do tipo ou tipos de discurso a gravar. Socorrendo-nos das definições usadas no sistema de metadados da iniciativa IMDI (IMDI 2003 e Hellwig \& Uytvanck 2007), podemos caracterizar os dados a recolher em termos de género, subgénero, tarefa e modalidades contempladas.

Se pretendermos, por exemplo, fazer a recolha de discurso espontâneo correspondente a um pedido de informação numa biblioteca ou numa bilheteira de transportes públicos, incluindo áudio e vídeo, podemos categorizar esses dados, conforme o esquema adiante apresentado, seguindo as setas.

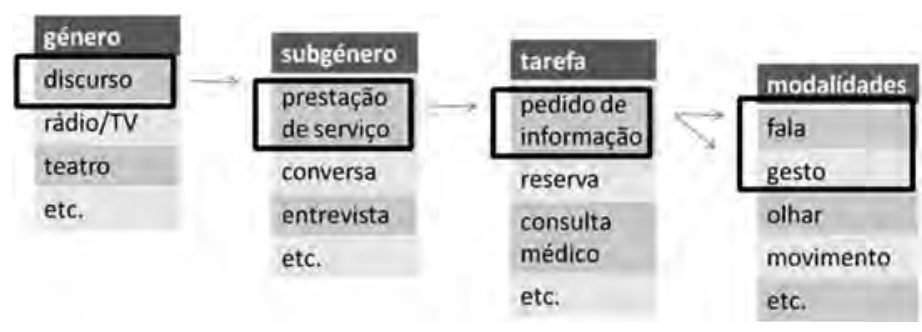

Figura 1

Categorização de dados correspondentes a um pedido de informação

Neste caso, o sistema de anotação adoptado para o corpus terá de incluir um nível para a transcrição de gestos, além dos níveis destinados à transcrição do sinal sonoro.

Importa também caracterizar os dados a recolher em termos do contexto comunicativo, considerando aspectos como o grau de interacção e planeamento do discurso, assim como o envolvimento dos participantes. No caso de uma conversa espontânea, podemos fazer uma categorização como a que nos indicam as setas: 


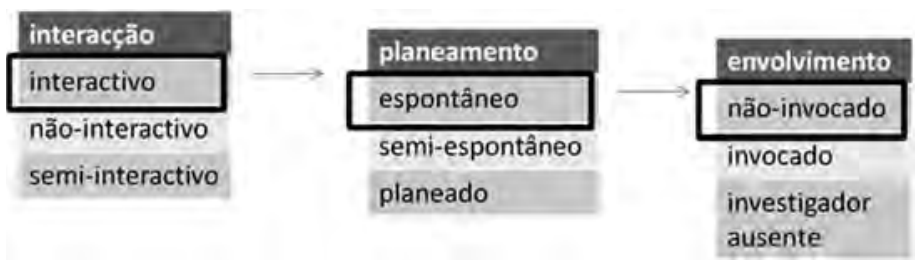

Figura 2

Categorização de dados correspondentes a uma conversa espontânea

Poderá haver casos em relação aos quais será difícil sermos taxativos, por exemplo se estivermos perante entrevistas ou narrativas que, ao longo da gravação, se tornam conversas entre investigador e informante.

Ainda a respeito do contexto comunicativo, é conveniente determinar o tipo de situações em que haverá gravação de fala tendo em conta a relação entre os intervenientes, a estrutura do discurso e o canal usado. Se se tratar de uma conversa entre familiares à mesa de refeições, podemos categorizar esse tipo de dados, recorrendo de novo a uma representação em esquema, da forma que se segue.

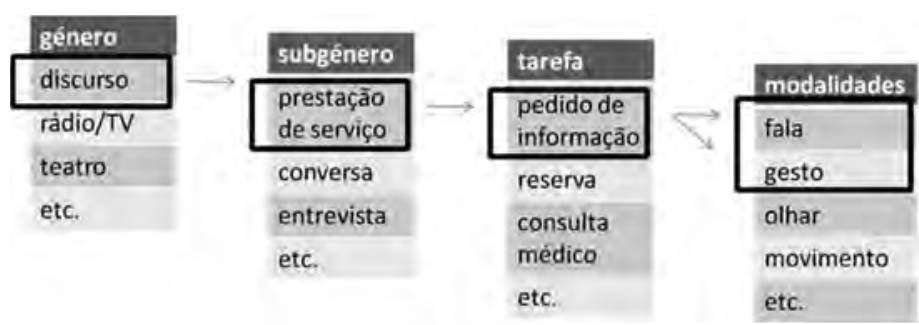

Figura 3

Categorização de dados correspondentes a uma conversa entre familiares à mesa

Também no que concerne às categorias acima se poderão verificar algumas situações que inspirarão dúvidas. No projecto CORP-ORAL, houve alguma dificuldade em classificar, em termos de canal, os dados correspondentes ao discurso de dois locutores que se encontravam jogando frente a uma consola Playstation. Nesse caso, uma solução possível é usar etiquetas menos descritivas como 'contexto experimental'. 


\subsection{Quantidade}

Quando falamos em corpora específicos, um aspecto normalmente referido é o das metas finais atingidas por esses corpora em termos de quantidade de dados. Essas metas podem ser quantificadas em termos de um número de palavras ou um número de horas gravadas a transcrever. No caso do C-ORAL-ROM, por exemplo, foi considerado que 300 mil palavras seria um conjunto representativo da fala espontânea de cada língua. Este tipo de quantificação poderá assumir particular importância para a gestão de um projecto de criação de corpus, sendo crucial por exemplo para determinar o número de pessoas necessárias para executar as tarefas de transcrição. Em todo o caso, devemos ter presente que os tempos de execução de tarefas como a transcrição variam muito em função do sistema e das ferramentas de anotação adoptadas e inclusive podem variar muito de transcritor para transcritor.

Até a relação entre o número de horas gravadas e o número de palavras transcritas dessas gravações pode oscilar em função do subgénero do discurso, do canal, etc. Consultando a tabela abaixo, que se baseia nos dados do C-ORAL-ROM, podemos constatar que o número de palavras transcritas por hora de gravação é superior no caso de se tratar de fala telefónica.

\begin{tabular}{|l|c|c|c|}
\hline $\begin{array}{l}\text { Tipo } \\
\text { de discurso }\end{array}$ & $\begin{array}{c}\text { Tempo } \\
\text { total }\end{array}$ & $\begin{array}{c}\text { Número } \\
\text { de palavras }\end{array}$ & $\begin{array}{c}\text { Palavras por } \\
\text { hora gravada }\end{array}$ \\
\hline Fala telefónica (PT) & $6 \mathrm{~h}$ & 85.573 & 14.262 \\
\hline Fala em geral (PT) & $26 \mathrm{~h}$ & 295.803 & 10.962 \\
\hline Fala em geral (FR) & $29 \mathrm{~h}$ & 317.916 & 11.377 \\
\hline
\end{tabular}

Tabela 1

Indice do número de palavras transcritas por bora gravada no C-ORAL-ROM, considerando diferentes tipos de discurso e diferentes linguas

Tendo em conta estes números, é possível estimar que são necessárias entre 70 e 100 horas de gravação para atingir um milhão de palavras ortográficas transcritas. Não é de estranhar que, no caso do CGN, 900 horas de gravação tenham dado origem a aproximadamente 9 milhões de palavras transcritas.

\subsection{Ubiquidade de recursos}

Um aspecto que importa sublinhar, a propósito da recolha de dados, é a ubiquidade de recursos graváveis que presenciamos nos nossos dias. $\mathrm{O}$ in- 
vestigador tem ao seu dispor uma superabundância de canais de gravação que vão do telefone aos meios de comunicação institucionais, passando naturalmente pela internet e terminando nos circuitos de vigilância feita em espaços públicos e privados. Oferecendo diferentes graus de qualidade acústica e de imagem, assim como os mais variados tipos de discurso, esta ubiquidade de recursos poderá facilitar consideravelmente o processo de recolha de dados, dispensando a aquisição de equipamento e a realização de sessões de gravação específicas.

\subsubsection{Telefone}

O telefone é um dos meios pelos quais mais facilmente se pode recolher discurso espontâneo, com a vantagem de que apenas nos temos de preocupar com o áudio. A fala telefónica em si própria tornou-se objecto de estudo linguístico e sociológico, e o fulgurante desenvolvimento da telefonia móvel veio trazer um renovado interesse pelo assunto.

As gravações de dados telefónicos podem ser feitas, por exemplo, em colaboração com os operadores de rede fixa, solução que foi adoptada para a componente portuguesa do C-ORAL-ROM. Nesse caso, foi possível obter ficheiros de áudio com separação de canais por falante. Essas gravações, codificadas em formato digital WAV não-comprimido de $8 \mathrm{Khz}$, apresentam boa qualidade acústica, sendo passíveis de análise fonética detalhada.

A separação de canais é um elemento que não deve ser sonegado nas gravações, uma vez que pode facilitar consideravelmente o trabalho de transcrição. Não existem, no entanto, grandes opções para consegui-lo em recolhas telefónicas, e o mais simples é mesmo solicitar a cooperação dos operadores de telecomunicações do país. Caso contrário, será necessário recorrer a modelos híbridos de telefone, o que implica custos adicionais consideráveis.

A dificuldade em obter a separação de canais e as instabilidades de sinal que se verificam com as chamadas na rede móvel poderão constituir um obstáculo à recolha de telefonemas feitos entre telemóveis. No entanto, a facilidade com que é possível obter tais gravações serve como contrapeso a essas duas limitações técnicas. Hoje em dia muitos dos modelos de telemóvel disponíveis no mercado permitem a gravação de chamadas. Alguns incluem a possibilidade de gravação em formato não-comprimido de $8 \mathrm{Khz}$. Modelos equipados com o sistema operativo Symbian S60 de terceira geração, por exemplo, suportam esse formato e permitem inclusive a instalação de aplicações próprias para fazer gravações de forma totalmente automática. Com dispositivos desse tipo, é relativamente fácil obter dados de informantes dispostos a contribuir para uma recolha. 
O facto de os ficheiros obteníveis via telemóvel serem monofónicos não é, de todo, um argumento impeditivo para a sua colheita e utilização. Estudos como os que se apresentam em Luke \& Pavlidou (2002) foram todos conduzidos com base em gravações monofónicas, alguns usando até formas de recolha artesanais, o que mostra que esse tipo de dados pode ser utilizado em análises de grande alcance.

Para obviar os problemas inerentes à constituição de corpora telefónicos a partir do zero, uma das saídas possíveis é a utilização de dados previamente coligidos. Grande parte das companhias que prestam serviços ao público fazem a gravação das chamadas que entram e saem dos seus centros de atendimento. Esses dados reúnem comunicações correspondentes à prestação de serviço em geral, podendo incluir não só pedidos de informação mas também chamadas de serviço, campanhas de telemarketing, reclamações, etc. Existem na literatura brasileira vários exemplos de análise baseada em recolhas deste tipo, sendo Reis (2004) um caso a considerar.

\subsubsection{Meios de comunicação social}

Os meios de comunicação social constituem outra fonte de dados que permite fazer recolhas de fala de forma rápida e pouco dispendiosa. Têm a vantagem, em comparação com o telefone, de suportarem uma banda de frequências sonoras muito mais larga e poderem incluir a imagem.

Embora o discurso dos pivôs que lêem os noticiários seja normalmente estilizado, outros tipos de programa existem onde a linguagem usada se aproxima ou reflecte mesmo o discurso usado pelos falantes no dia-a-dia. Destinado a recolher unicamente dados deste tipo, o projecto REDIP (Mateus \& Bacelar do Nascimento 2005), que inicialmente havia sido pensado como uma extensão portuguesa do projecto DIES-RTP (Avila 1999), reuniu cerca de 220 mil palavras da rádio e televisão lusas incluindo algum material que pode ser classificado como fala espontânea. Foi sobretudo nos programas de debate e entrevista, por exemplo nos que eram dedicados a temas desportivos, que se verificou uma maior tendência para a informalidade no discurso. O advento dos reality shows e afins, nos últimos anos, veio incrementar a presença desse tipo de fala nas transmissões televisivas.

Por outro lado, mesmo o discurso lido ou altamente preparado dos noticiários e programas análogos pode ser de utilidade para algumas análises. Não é de estranhar, por isso, que no C-ORAL-ROM tenham sido incluídas diversas gravações desse tipo originárias do corpus REDIP.

A cooperação com as emissoras no processo de recolha é, neste caso, fundamental, não só pelo que diz respeito à obtenção das autorizações ne- 
cessárias à utilização do material mas também no que respeita à consecução das próprias gravações. Embora seja possível fazer recolhas de alta qualidade mesmo recorrendo a aparelhos de uso doméstico, é preferível optar pelas gravações feitas nos próprios estúdios, sobretudo no caso da rádio (Ramilo \& Freitas 2002a).

A internet merece um destaque especial no capítulo dos meios de comunicação, visto que em muitos aspectos passou a incorporar todos os outros meios. A última década veio, com efeito, trazer um aumento significativo de conteúdos áudio e vídeo publicados na rede, tendo também sido marcada pela implementação em definitivo do sistema VoIP, entre outros.

A crescente adopção da telefonia pela internet é um fenómeno que também deve ser tido conta para a recolha de dados, visto que esse sistema de comunicação apresenta importantes vantagens sobre as chamadas telefónicas comuns. Em primeiro lugar, suporta uma largura de onda áudio maior. Em segundo lugar, inclui já a possibilidade de recolher o vídeo correspondente a cada um dos comunicantes em ficheiros separados.

A incorporação dos outros meios na internet implica, por outro lado, que muitos dos programas veiculados na rádio e televisão passaram a ser graváveis pela rede. Mais do que isso, a internet veio estimular o desenvolvimento de novos formatos de publicação, como o podcast, que permitem automatizar por completo o processo de recolha. Embora os formatos digitais usados para difundir esses conteúdos sejam muitas vezes de baixa resolução, existem já algumas iniciativas desenvolvidas no sentido de criar infra-estruturas de rede capazes de suportar a transmissão de imagem e som de alta definição (Zimmermann 2004).

\subsubsection{Contexto presencial}

As duas subsecções anteriores têm por objectivo enfatizar a facilidade com que é possível recolher dados orais nos dias que correm, mas a verdade é que nenhuma se referia à produção de discurso no seu contexto mais natural: a comunicação de viva voz. Esse será, de resto, o tipo de recolha mais adequado para obter gravações áudio ou vídeo de alta resolução. A importância dada a estes dois aspectos, a naturalidade e a qualidade dos dados obtidos, foi o que determinou a opção pela fala presencial em projectos como o CORP-ORAL.

O formato da gravação áudio é, assim, um dos aspectos importantes a considerar. Embora os formatos de compressão mais comuns, como o ATRAC, MP3 e Ogg Vorbis, não sejam considerados problemáticos para efeitos de análise acústica (van Son 2002), mesmo para utilização em aplicações computacionais (Campbell 2002a), é recomendável fazer gravações em for- 
matos digitais não-comprimidos de alta definição (CDP 2005). Os gravadores portáteis comercializados nos nossos dias já suportam na sua maioria essa alta resolução, e alguns como o Korg MR-1 e MR-1000 incluem até possibilidades de codificação alternativa como o Direct Stream Digital, de 1 bit, usado no suporte SuperAudioCD.

A utilização de formatos de alta resolução torna as colecções, por assim dizer, 'à prova de futuro', tendo em conta que equipamentos de áudio e vídeo compatíveis com esses formatos já começam a estar disponíveis mesmo no sector doméstico. Com o crescente desenvolvimento da tecnologia de rede, não tardará a ser possível aceder a grandes colecções de áudio gravadas em formato de alta definição com uma simples ligação à internet. Por outro lado, é possível converter áudio de $192 \mathrm{Khz}$ para $44 \mathrm{Khz}$, para utilização em programas de análise de fala como o Praat (Boersma \& Weenik 2007), mas não é possível transformar uma gravação de $44 \mathrm{Khz}$ numa genuína gravação de alta resolução.

A tabela 2 apresenta alguns dos modelos de gravadores áudio portáteis disponíveis no mercado. Os quatro modelos apresentados já foram ou estão a ser usados em projectos de recolha de fala do português.

\begin{tabular}{|c|c|c|c|c|}
\hline Marca & Modelo & $\begin{array}{c}\text { Suporte } \\
\text { de escrita }\end{array}$ & Observações & $\begin{array}{c}\text { Preço } \\
\text { aproximado }\end{array}$ \\
\hline Zoom & H2 & $\begin{array}{c}\text { cartão de } \\
\text { memória }\end{array}$ & $\begin{array}{c}\text { microfone } \\
\text { incorporado }\end{array}$ & $€ 200$ \\
\hline Sony & MZ-RH1 & minidisco & sem microfone interno & $€ 300$ \\
\hline Korg & MR-1 & disco rígido & $\begin{array}{c}\text { sem microfone interno, } \\
\text { grava em formato DSD }\end{array}$ & $€ 600$ \\
\hline Marantz & PMD-671 & $\begin{array}{c}\text { cartão de } \\
\text { memória }\end{array}$ & sem microfone interno & $€ 1000$ \\
\hline
\end{tabular}

Tabela 2

Gravadores digitais portáteis com diferentes especificações e gamas de preços

A estas opções junta-se também a possibilidade de fazer as gravações directamente para um computador portátil, havendo hoje uma vasta gama de placas de som externas disponíveis para o efeito, de que são exemplo a Sound Devices USBPre e a M-Audio.

Potencialmente mais importantes do que o gravador usado são, todavia, factores como o tipo de microfone escolhido e a colocação do mesmo (Campbell 2002b e van Son 2002). A preferência vai para microfones com armação montados de maneira a que a cabeça do dispositivo fique o mais perto possível da boca do falante, mas evitando as trajectórias de saída de ar oral e nasal (Campbell 2002b). 
Relativamente aos modelos de microfone propriamente ditos, a opção deverá ser sempre ditada pelo tipo de ambiente em que as gravações terão lugar. Autores como Bartlomiej Plichta recomendam a utilização de microfones Sennheiser HME-25-1 para ambientes ruidosos. Alternativas a esse modelo serão o Coles 4104B, o Shure WH20 e o Sennheiser NB2 (Campbell 2002b). Para gravações em salas silenciosas o projecto CORP-ORAL emprega microfones Beyerdynamic Opus 55.18, tendo também considerado o uso do Shure SM10A. Já para captação em estúdios insonorizados ou câmaras anecóicas, as recomendações vão para o Earthworks M30 ou o menos dispendioso Behringer ECM8000, também de acordo com Bartlomiej Plichta. Para gravações dissimuladas (cf. 3.4), em que é vital que os participantes não se apercebam da presença de um microfone, existem alguns modelos especificamente desenhados para o efeito como o Core Sound Stealthy, o Lombardo Lapel Mic, o Sonic Studios DSM-1 e o Sound Professionals SP-TFB-2 (estes facilmente disfarçáveis como auriculares).

\subsection{Dimensão ética e legal}

Um aspecto não menos importante da recolha é o dos procedimentos éticos e legais que rodeiam o processo de gravação. Nem todas as instituições universitárias têm códigos de conduta explícitos no que respeita à regulação das pesquisas linguísticas. Existem, em todo o caso, recomendações gerais que podem ser seguidas e que se encontram publicadas por organismos como a BAAL (cf. BAAL 2006).

O principal problema que se levanta, neste domínio, é o da obtenção de consentimento declarado por parte dos participantes nas recolhas. Esta questão pode, com efeito, ser considerada um problema no sentido em que as autorizações pessoais explícitas condicionam o carácter espontâneo dos dados. Assim, e tendo em conta que o uso de gravações não-autorizadas é uma opção a evitar (cf. Shuy 1993), o ideal é recorrer a formas criativas, mas legalmente bem definidas, para a obtenção desse consentimento.

A realização de gravações dissimuladas, em que os participantes apenas são informados do acto da recolha após a mesma ter sido efectuada, é uma das soluções possíveis. Uma outra possibilidade, que foi implementada na componente portuguesa do C-ORAL-ROM, é combinar com os informantes a gravação de uma conversa específica dentro de um conjunto de conversas realizadas num determinado período de tempo, sem que aqueles sejam informados do momento exacto em que serão gravados. Trata-se de um procedimento fácil de executar por exemplo com chamadas telefónicas.

Métodos como os que foram acima referidos poderão, dependendo do 
país, roçar os limites da legalidade. O ordenamento jurídico espanhol, por exemplo, é bem mais específico que o português em relação à prática de registos de voz e de comunicações em geral (Abud 2005). Além disso, a recolha de vídeo a par do áudio poderá comportar, a esse respeito, adversidades adicionais.

\subsection{Recrutamento dos participantes}

É devida ainda uma nota relativa ao modo de recrutamento dos participantes para as gravações em contexto presencial. Em projectos de pequenas dimensões, como o CORP-ORAL, a solução encontrada para minimizar custos muitas vezes passa por solicitar a colaboração voluntária de colegas, conhecidos, familiares e amigos. Essa é, no entanto, uma estratégia que implica algumas contrapartidas, nomeadamente a negociação idiossincrática das sessões de gravação.

Em projectos de larga escala que envolvam a gravação de centenas ou milhares de horas de fala, o mais adequado é recorrer a uma agência de contratação. Desse modo, é mais fácil obter dados de diferentes estratos da população de acordo com um plano balanceado. Essa é também a solução indicada para garantir que as recolhas serão concluídas dentro dos prazos estipulados.

\section{ANOTAÇÃO DOS DADOS}

Quando se fala de anotação de dados, é costume falar em primeiro lugar de transcrição ortográfica. Embora hoje em dia já estejam popularizados muitos outros tipos de anotação, por exemplo em investigações etnográficas (Duranti 1997), é indiscutível que a transcrição da fala feita de acordo com a grafia veicular da língua continua a desempenhar um papel primordial em qualquer colecção de dados orais.

O desenvolvimento das ferramentas computacionais de reconhecimento de fala permite que, nos tempos que correm, seja já possível fazer esse trabalho de transcrição ortográfica de modo automático. Dependendo do tipo de fala e das condições acústicas da gravação, é possível obter transcrições com taxas de erro tão baixas como 11 por cento em línguas como o português europeu (Amaral et al. 2007).

É claro que a performance das aplicações de transcrição automática tenderá a baixar consideravelmente se se tratar de fala espontânea ou, pior, de fala espontânea gravada em ambientes com algum ruído. Essa é, contudo, 
uma hipótese de trabalho que não deve ser deixada de parte na fase de preparação do corpus, durante o projecto-piloto, para aferir se o tempo que os anotadores terão de despender a corrigir uma transcrição ortográfica automaticamente gerada poderá ser inferior ao tempo que demoram eles próprios a fazer essa transcrição.

\subsection{Fundamentação da transcrição ortográfica}

A propósito da realização de transcrições ortográficas, os construtores e consumidores de corpora orais por vezes esbarram com a seguinte questão: não deveria a ortografia, conotada como está com a ideia de neutralização da oralidade e inevitável favorecimento de um dialecto sobre outro, ser o nosso último recurso para representar a riqueza de expressão e pronúncia por que se caracteriza o oral? Não seria mais útil tentar dar conta da variação sonora da língua com uma grafia diferenciada? Concretizando a pergunta com o caso específico do português, não seria mais adequado fazer a distinção entre variantes como <estar $>$ e < tar $>$ consoante a presença ou ausência da sibilante na forma realmente produzida pelos falantes transcritos?

Esta questão já foi antes discutida por autores como Bacelar do Nascimento et al. (1987) e será aqui explorada com algum detalhe. Em primeiro lugar, torna-se contraproducente condensar diferentes tipos de informação num único nível de representação (Ochs 1979, Coates \& Thornborrow 1999): dificilmente aceitaremos a ideia de representar os gestos e os olhares trocados pelos participantes de uma conversação na mesma linha em que representamos as palavras que estão a dizer. Do mesmo modo, podemos pensar que a maneira de pronunciar e entoar uma sequência de fala cabem em níveis de transcrição distintos do das palavras que são ditas. Acima de tudo, é preciso encarar a transcrição como um processo de análise necessariamente redutor e selectivo (cf. Duranti 1997 e Walker 2004, entre outros, para discussões recentes deste aspecto) que pode ser sempre aperfeiçoado.

Em segundo lugar, é importante ter em conta que a variação na oralidade não se reduz a oposições tão cristalinas como a de [tar] e [jtar]. Socorrendo-nos novamente do português, pensemos numa palavra tão recorrente como a preposição <para>: apesar de ser grafada com quatro letras, dificilmente conceberemos que alguma vez na oralidade seja produzida com o equivalente a quatro segmentos. Com efeito, se examinarmos as realizações fonéticas que esse item lexical recebe nas conversas espontâneas do CORPORAL, por exemplo, verificaremos que normalmente correspondem a apenas um ou dois segmentos: $[\mathrm{p}]$ ou $[\mathrm{pr}]$. Em casos excepcionais poderá realizar-se como [ргъ]. Em face desses factos, uma opção seria propor que se 
passasse a usar as grafias $\langle$ p $>,<$ pr $>$ e $<$ pra $>$, eventualmente com o auxílio de um apóstrofo, para representar tais realizações. Nesse caso, teríamos também de prever o emprego das formas <pà> e <pò> para representar as sequências em que a preposição se encontra com o artigo feminino e masculino, o que muitas vezes resulta nas realizações [pa] e [po].

O tipo de detalhe acima ilustrado constituirá, todavia, uma importante sobrecarga no trabalho do transcritor, obrigando-o a rever cuidadosamente cada uma das instâncias da preposição que estiver a transcrever. Em muitos casos, dependendo do contexto em que a palavra se encontrar e das características acústicas do trecho de fala, essa decisão tornar-se-á particularmente difícil. Além disso, a preposição para é apenas um dos inúmeros vocábulos susceptíveis de redução fonética que encontramos no português europeu. Não será legítimo decidir à partida que as variantes de para, por serem mais fáceis de elencar numa lista de convenções de transcrição, devem ser contempladas com uma grafia modificada em detrimento de outras menos fáceis.

Se procurarmos abarcar a abrangência do fenómeno da redução segmental em línguas como o português europeu e os problemas de percepção que lhe estão implícitos (reportados, entre outros, em Amaral 1998), depressa chegaremos à conclusão de que propor uma grafia modificada que dê conta de todas as possibilidades é tarefa impossível. Palavras como desprestigiado e suficiente, por exemplo, tendem a ser produzidas com um único segmento identificável como uma vogal, mas dificilmente se aceitará que as representemos com grafias modificadas como $<$ dsprstgiad $>$ e $<$ sfcient $>$.

A figura abaixo apresenta o espectrograma correspondente à produção da palavra suficiente numa das conversas do CORP-ORAL. O silêncio que encontramos do lado direito condiz, na verdade, com a oclusão que resulta da sequência das consoantes $<\mathrm{t}>$ e $<\mathrm{p}>$ no contexto suficiente para, o que atesta a inexistência de qualquer segmento vocálico após a oclusiva dental. Da observação do lado esquerdo do espectrograma torna-se também evidente a ausência de qualquer segmento vocálico que preceda a semivogal [j]. Temos, assim, que a única vogal identificável nesta sequência é a acentuada [ẽ]. Note-se que esta forma foi realizada por uma das falantes da faixa etária mais elevada do corpus, podendo ser considerada uma representante conservadora do dialecto-padrão do português europeu. 


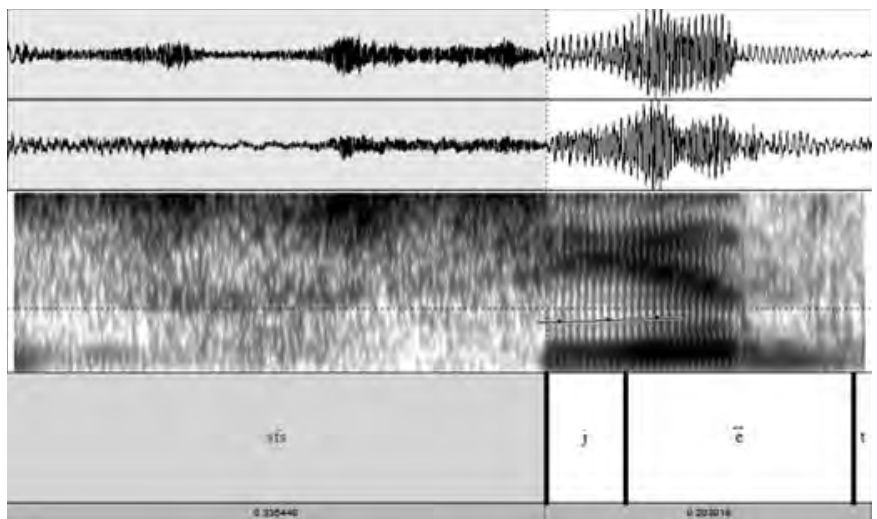

Figura 4

Onda sonora, espectrograma e transcrição fonética da palavra suficiente no contexto suficiente para (CORP-ORAL, O21, 23.31)

Hipóteses de transcrição como < dsprstgiad > e <sfcient> conduzem-nos a uma outra questão: a da legibilidade das grafias modificadas. Ainda que seja possível identificar palavras no meio de sequências de consoantes, após algum treino, é indiscutível que o uso das formas ortográficas acelerará de forma incomparável a leitura das transcrições. Isto além de acelerar consideravelmente a tarefa de transcrição, descomprometendo o transcritor de decisões potencialmente arbitrárias sobre a natureza fonética das formas em análise.

Outra das razões por que seria tão moroso implementar um sistema de grafias modificadas para a transcrição do português europeu prende-se com o facto de não haver nenhuma tradição ou código estabelecido para a aproximação da escrita ao oral. Existirão, sim, algumas invenções feitas nesse sentido (Marquilhas 2004). O grau de adopção e de consistência no uso dessas invenções é, contudo, desconhecido.

Tendo em conta os argumentos acima explanados, não é de estranhar que a história dos corpora orais do português tenha privilegiado o uso das formas ortográficas (Bacelar do Nascimento 2005). Mesmo para línguas como o inglês, em que existem fortes tradições estabelecidas no uso de grafias modificadas, por exemplo no domínio da análise da conversação, verifica-se uma preferência explícita pelo emprego da escrita-padrão em trabalhos recentes (Coates \& Thornborrow 1999 e Walker 2004).

Uma última razão para favorecer o uso da ortografia na transcrição das palavras que são ditas na fala espontânea, citada já em Bacelar do Nascimento (2003), é o facto de hoje em dia podermos contar com ferramentas 
robustas para fazer o alinhamento entre o áudio original e o texto transcrito (cf. 4.3), permitindo reunir ambos os conteúdos num mesmo suporte. Dessa forma, fica o consumidor do corpus habilitado a, numa consulta fortuita, saber exactamente como foram pronunciadas as ocorrências de para, por exemplo, sem ter de se preocupar em introduzir variantes como $\langle$ p $>$, $\langle$ pà $>$, $<$ pá>, <pò>, <pó>, <pr> e <pra> no motor de busca.

\subsection{Tempo e preço da transcrição manual}

À discussão acima exposta subjaz uma preocupação evidente com o tempo e o preço que custa a transcrição manual de corpora orais. Trata-se, efectivamente, de uma tarefa lenta e dispendiosa.

No projecto CORP-ORAL, por exemplo, o tempo médio de fala transcrito por dia, por cada transcritor, varia entre os três e os cinco minutos, considerando turnos de trabalho diário de cinco horas. Corresponde, portanto, a um ritmo máximo de transcrição de um minuto de fala por hora.

É claro que o tempo de execução da tarefa depende muito do tipo de transcrição e das ferramentas utilizadas. No caso do CORP-ORAL, o transcritor tem de escrever as palavras que são ditas por cada um dos participantes da conversa em linhas independentes, ao mesmo tempo que tem de fazer o alinhamento manual dessas sequências e anotar fenómenos como a ocorrência de fronteiras prosódicas, fenómenos paralinguísticos como o uso de cliques e ainda a manifestação de respirações e ruídos de fundo, tudo isto usando o programa ELAN (Hellwig \& van Uytvanck 2007a), que não é de modo nenhum uma ferramenta desenhada para acelerar o processo de transcrição (Farrar et al. 2006).

Tendo em conta o ritmo de trabalho supracitado e os valores correspondentes ao rendimento médio dos bolseiros de investigação em Portugal, foi determinado que os tarefeiros responsáveis pela transcrição ortográfica do CORP-ORAL receberiam 500 euros por cada hora de áudio transcrita nas condições referidas.

Existirão maneiras de reduzir eficazmente o tempo e o preço deste tipo de trabalho. Em relação ao primeiro aspecto, uma das mais adequadas será, sem dúvida, usar exclusivamente gravações com separação de canais, já que a ocorrência de sobreposições, regra geral muito frequentes em fala espontânea, estorva o trabalho de descodificação levado a cabo pelos transcritores. Já no que respeita à questão monetária, uma opção a considerar é o recurso a estudantes universitários que possam fazer a tarefa voluntariamente. Contudo, as considerações tecidas em 3.5 sobre o recrutamento de participantes aplicam-se, aqui, de modo ainda mais veemente. 


\subsection{Alinhamento manual das anotações}

Uma característica partilhada por boa parte dos corpora construídos nos últimos anos é o facto de apresentarem alinhamento das anotações com o áudio (e eventualmente o vídeo) gravado. Essa funcionalidade agiliza sobremaneira o processo de localização de excertos áudio específicos na utilização final do corpus, pelo que deverá merecer atenção redobrada.

Existem diferentes formas de produzir o alinhamento manual das anotações. Com o programa WinPitch (Martin 2004), por exemplo, o anotador pode alinhar textos anteriormente transcritos de um modo simples e intuitivo: depois de seleccionar o ficheiro de áudio e a respectiva transcrição, basta activar o modo de alinhamento e clicar, dentro da janela de texto, sobre a palavra que está a ser reproduzida em cada momento. Para facilitar o processo, o programa inclui comandos para controlar a velocidade de reprodução do áudio. Trata-se de um tipo de alinhamento assistido que permite poupar tempo quando se está a trabalhar com transcrições pré-existentes. Já o ELAN e o Transcriber (Manta et al. 2006) estão mais vocacionados para o alinhamento de transcrições feitas no próprio programa do que para o reaproveitamento de anotações previamente estabelecidas (Farrar et al. 2006).

Em qualquer dos três programas acima referidos a tarefa de alinhamento pode ser executada com maior ou menor precisão e tendo por alvo diferentes unidades linguísticas. No âmbito do CORP-ORAL, a opção foi por fazer o alinhamento de turnos de fala. Não é uma decisão isenta de críticas, até porque a definição de turno levanta alguns problemas (cf. Selting 2000 e Ford 2004). Tratou-se, com efeito, de uma decisão tomada no sentido de optimizar a velocidade de transcrição com o programa ELAN. Há que realçar, contudo, que a opção não teria sido menos problemática se o alinhamento tivesse por alvo unidades como a sílaba, a palavra ou a frase, implicando além disso, nesse caso, um dispêndio de tempo muito superior por parte dos transcritores.

\subsection{Limites da transcrição ortográfica}

Apesar de funcionalidades como o alinhamento virem a facilitar e até mesmo ratificar a opção pela ortografia, existem muitos limites ao uso desta numa transcrição do oral. Um dos aspectos normalmente referidos é o da incapacidade da escrita-padrão para dar conta da fragmentação do texto. A pontuação corrente de línguas como o português, além de padecer de sérias lacunas do ponto de vista funcional, não é adequada para representar as alterações prosódicas decorrentes da estruturação do discurso que os falantes fazem na sua oralidade. 
As vantagens e desvantagens do uso de diferentes sistemas de pontuação foram já amplamente discutidas em textos anteriores (Bacelar do Nascimento et al. 1987, Blanche-Benveniste \& Jeanjean 1987 e Ramilo \& Freitas 2002b, inter al.), e a tendência que se observa hoje em dia para representar a fragmentação de textos divide-se sobretudo em duas orientações distintas: ou fazer uma marcação prosódica simples baseada na sensibilidade acústica dos transcritores, método que tem conhecido bons resultados em termos de consistência (Moneglia et al. 2005), ou fazer uma caracterização detalhada dos períodos de pausa e sobreposição de fala, à moda da análise da conversação (Walker 2004).

Podemos considerar, no entanto, que mesmo a informação relativa à estruturação prosódica e as indicações de pausas cabem noutros níveis de representação e não devem estar misturadas com as palavras ortográficas. E, havendo neste momento programas de transcrição gratuitos, como o ELAN, que permitem adicionar um número infinito de fiadas de anotação, oferecendo ao mesmo tempo a possibilidade de inspecção visual directa da onda sonora, podemos considerar que realmente será melhor relegar esse tipo de informação estrutural para outros níveis, reservando a fiada ortográfica simplesmente para as palavras ditas.

Já não será tão pacífico, no entanto, querer representar falsas partidas, hesitações e marcas de retorno (por vezes transcritas em português europeu como <hum hum>) em níveis de representação separados do das palavras. Se tivermos em conta que as marcas de retorno também podem ser concretizadas por meio de expressões como pois, não fará muito sentido colocar a sequência hum hum numa fiada à parte só porque eventualmente tem um carácter 'menos ortográfico'. Uma solução para este problema, que foi posta em prática em projectos como o C-ORAL-ROM e o CORP-ORAL, passa por convencionar algumas grafias fixas para representar os fenómenos de hesitação e de retorno. Nas transcrições do primeiro projecto, fenómenos de hesitação são representados com a sequência <\&eh> (a utilização do símbolo $<\&>$ no início da sequência permite distinguir esses casos das instâncias da interjeição <eh>, que está listada nas obras lexicográficas); já as marcas de retorno são representadas com as letras $<$ hum $>$.

É evidente que uma solução desse tipo põe o ónus da decisão no transcritor, que terá de decidir, por exemplo na transcrição de um excerto em

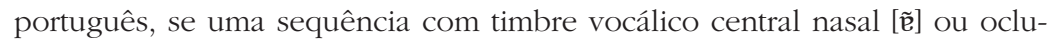
são bilabial longa e nasalidade [m:] será uma marca de retorno (representável como $<$ hum $>$ ) ou, pelo contrário, um pedido de reformulação (representável como $<$ hã $>$ ). Tendo em conta que estas unidades são geralmente produzidas com uma configuração tonal distinta, e normalmente não geram problemas de ambiguidade, podemos admitir que se torna preferível deixar essa res- 
ponsabilidade de interpretação com o transcritor ao invés de pedir-lhe que escreva uma grafia aproximada à configuração articulatória que pensa ter sido produzida naquele momento.

Existem, de qualquer maneira, algumas vantagens em registar os fenómenos acima referidos num domínio independente, por exemplo no caso de prevermos o tratamento computacional desses dados. Para esse tipo de aplicações, as falsas partidas, hesitações e marcas de retorno costumam ser agrupadas sob a designação de 'disfluências'. Uma opção conveniente, também permitida pelos modernos programas de transcrição, será então começar por fazer a transcrição desses fenómenos numa fiada à parte e depois copiá-los para a fiada ortográfica. Este tipo de tratamento também poderá ser dado aos casos de interjeições incomuns e outros sons com função paralinguística, como os cliques, cuja representação poderá colidir com o uso da ortografia simples.

Ainda um outro nível em que as transcrições tendem a afastar-se da escrita normalizada é o da utilização das letras maiúsculas. Tomando novamente por referência os projectos C-ORAL-ROM e CORP-ORAL, que neste aspecto se aproximam da resolução que antes havia sido adoptada para o NURC (Castilho \& Pretti 1987), deveremos restringir o uso dessa grafia a nomes próprios e a siglas. Por vezes será problemático saber exactamente o que é um nome próprio (Bacelar do Nascimento et al. 2005), mas é desejável incluir nessa categoria não só os antropónimos e topónimos mas também entidades como nomes de empresas e de grupos artísticos e os títulos de obras de arte e publicações. No caso de estarmos perante abreviaturas correspondentes a acrónimos listados no dicionário, são usadas letras minúsculas (Bacelar do Nascimento et al. 2005).

Já em relação aos estrangeirismos, o mais conveniente será escrevê-los de acordo com a ortografia, no caso de já estarem listados nos dicionários, mas incluindo uma etiqueta com a indicação de que se trata de palavras estrangeiras, de modo a chamar atenção para eventuais questões de pronúncia. No caso de não haver uma proposta ortográfica para a representação da palavra, deverá ser seguida a grafia da língua de origem tanto quanto possível. Naturalmente no caso de palavras do chinês e do japonês, por exemplo, essa solução não será facilmente adoptável, pelo que o mais fácil é seguir as grafias internacionais (normalmente estabelecidas pelos falantes anglo-saxónicos) correntemente usadas para esses vocábulos.

\subsection{Revisão}

Dentro do capítulo da transcrição, importa ainda falar do processo de revisão, que é essencial para assegurar a consistência dos dados finais inscritos 
no corpus. Hoje em dia, com o advento de programas de transcrição como o ELAN, que permitem um número infinito de fiadas de anotação, o mais indicado é proceder à revisão de uma maneira não-destrutiva, preservando todos os dados estabelecidos pelo transcritor original e mantendo as alterações feitas pelo revisor num nível à parte.

A revisão deverá ser feita pelo menor número de pessoas possível, idealmente apenas pelo coordenador das tarefas de transcrição, de modo a que a consistência seja máxima. É evidente que se torna impensável ter um só investigador responsável por assegurar a consistência da transcrição de um corpus de muitas horas de fala. O mais sensato será organizar reuniões de discussão regulares entre a equipa de transcritores e uma equipa de revisão, de modo a que os problemas encontrados sejam debatidos e uma solução possa ser estabelecida para referência dos revisores. Sendo impossível reunir regularmente toda a equipa, há sempre a hipótese de recorrer a um sistema de relatórios de inconsistências, como aconteceu no CGN (Schuurman et al. 2004).

\section{ORganizaC̣̃̃o E MANUTENÇ̃̃O DOS DADOS RECOlHIDOS}

Mesmo antes de estarem recolhidos e transcritos os dados, convém ter uma ideia de como devem ser organizados e mantidos. Existem diferentes modelos para a estruturação dos documentos produzidos no decurso de um corpus. Um que é recomendável, por estar publicamente acessível na internet e ser continuamente actualizado, é o da iniciativa IMDI. No âmbito deste projecto, são inclusive disponibilizadas ferramentas muito úteis para o trabalho de organização, como o programa IMDI Editor (Hellwig \& van Uytvanck 2007b), que permite fazer uma codificação dos metadados do corpus (de acordo com categorias como as que foram discutidas em 3.1) de modo bastante intuitivo e sistemático.

\subsection{Anonimização}

Um dos aspectos que poderá ser necessário salvaguardar, dependendo do tipo de autorizações obtidas aquando do processo de recolha, é o anonimato de todos os participantes nas gravações.

Programas como o IMDI Editor permitem criar ficheiros de tabelas próprios com correspondências entre os nomes reais das pessoas que gravaram e códigos arbitrários atribuídos no projecto. Deste modo, a anonimização fica assegurada na estrutura de metadados. 
Um outro aspecto da anonimização que se poderá revelar particularmente problemático é o dos nomes de pessoas citados no discurso gravado, incluindo os próprios locutores. Usando programas como o ELAN, que permitem fazer pesquisas e substituições automáticas em colecções de ficheiros de transcrição, é relativamente simples fazer essa anonimização. No caso de ser necessário alterar todos os nomes de pessoas, será necessário primeiro fazer uma pesquisa usando expressões regulares para localizar todos os nomes transcritos com letra maiúscula.

\subsection{Manutenção}

É fundamental conceber a manutenção dos dados inscritos no corpus como um processo aberto no qual será sempre possível introduzir alterações (Schuurman et al. 2004). Essa acessibilidade poderá ser assegurada por exemplo por intermédio de uma interface de comunicação via internet, no caso de os dados virem a ser disponibilizados por esse meio. De qualquer maneira, é conveniente ter um sistema de centralização dos documentos estabelecidos no corpus, digamos que uma matriz, para que depois seja fácil introduzir e ter controlo sobre quaisquer alterações feitas a posteriori.

\section{DisPonibilizaÇÃO DO CORPUS}

O advento da internet veio introduzir modificações significativas na maneira como a disponibilização dos dados é pensada. Agora é possível aceder a corpora com muitos milhões de palavras, ao texto e ao áudio, com apenas alguns cliques de rato. Os desafios que se põem aos métodos de disponibilização passam sobretudo pela programação informática em linguagens como Java e PHP e pela concepção de bases de dados rápidas em servidores.

A principal questão que se coloca, neste domínio, é a de decidir se os dados devem ser inteiramente disponibilizados ou não. Isto é, se se deve dar acesso irrestrito à totalidade do corpus, incluindo os ficheiros contendo o áudio na resolução máxima e o texto completo das trancrições, ou apenas permitir que os consumidores finais façam consultas ou pesquisas específicas por palavras ou sequências de símbolos.

Grandes corpora como o Corpus de Referência do Português Contemporâneo (CRPC), do Centro de Linguística da Universidade de Lisboa (CLUL), encontram-se disponíveis na internet apenas para consulta, obrigando à formulação de pedidos formais no caso de o consumidor estar interessado em 
obter a matéria-prima correspondente. Outros, como o C-ORAL-ROM, estão disponíveis para aquisição para fins comerciais ou de investigação, com preços que variam entre os 1.500 e os 10.000 euros.

As ferramentas existentes na internet para a realização dessas consultas são muitas vezes modelizadas a partir dos corpora concretos, o que está acontecendo com o CORP-ORAL, que ficará disponível para consulta por intermédio do Spock, programa da autoria de Maarten Janssen que está neste momento em fase de desenvolvimento e pode ser testado em http://www.iltec.pt/spock/

\section{SÍNTESE}

Foram abordados ao longo deste texto vários aspectos mais ou menos específicos da constituição de corpora orais, considerando sobretudo os processos de recolha e transcrição ortográfica. Outros tópicos teriam merecido igual atenção, como a etiquetagem morfo-sintáctica e a transcrição fonética. Havia ainda que apreciar com maior detalhe temas como a recolha de fala em vídeo, mas por agora apenas poderei remeter esse e outros assuntos para um trabalho futuro.

Especificamente no que diz respeito à recolha de dados, foi explorada com insistência a ideia de que existe hoje em dia uma ubiquidade de dados graváveis, facto que deverá ser aproveitado pelos investigadores do oral. Foram discutidos em detalhe os aspectos relativos à gravação de conversas em meios como o telefone, tendo sido depois expostos alguns métodos de recolha de fala em contexto presencial.

No que respeita à transcrição do oral, tarefa assaz delicada e que exige considerável grau de persistência, foram discutidas as razões por que se torna mais adequado pensar no uso da ortografia ao invés de querer usar grafias modificadas, tomando por exemplo o que se passa no português europeu. Foram dados vários argumentos contra o uso destas últimas, alguns dos quais relacionados com o custo das tarefas de transcrição.

Não ficaram por referir, no entanto, os problemas que se põem com a utilização da ortografia, tendo sido abordadas questões específicas como a estruturação do texto e a representação de falsas partidas, hesitações e marcas de retorno. Foram avançadas algumas hipóteses de resolução desses problemas.

A par destes tópicos, foram considerados por alto os processos de planificação, organização, manutenção e disponibilização dos corpora orais, processos que têm recebido muita atenção na literatura da especialidade da últi- 
ma década. A constituição de corpora deste tipo tem vindo a conhecer fortes impulsos durante este período, por exemplo no campo das línguas em vias de extinção, o que se deve não só aos impressionantes desenvolvimentos da tecnologia, que vieram facilitar e muito o trabalho de recolha e transcrição, mas também a um renovado e justificável interesse dos linguistas por aquilo que é, de facto, a realização primeira da língua.

\section{AgRAdeCIMENTOS}

Devo um agradecimento especial ao Miguel Oliveira, Jr., não só por me ter apresentado algumas das técnicas acima descritas mas também pelos comentários feitos a este texto e pelas conversas que ao longo dos últimos anos tivemos sobre diferentes métodos de gravação e transcrição do oral. Agradeço à Fabíola Santos e à Lis Gonçalves as discussões que pacientemente foram tendo comigo enquanto transcreviam os diálogos do CORP-ORAL. Importa igualmente agradecer à audiência do Simposio ILG as perguntas feitas no seguimento da conferência e à equipa do ILTEC os comentários dirigidos a uma apresentação prévia da mesma. Cabe ainda uma menção à equipa do CLUL, pioneira neste tipo de trabalho para o português, pela disponibilidade que sempre mostrou para partilhar o seu conhecimento e experiência.

\section{REFERÊNCIAS BIBLIOGRÁFICAS}

(Endereços da internet de 31.01.08)

Abud, T. (2005): "As interceptações das comunicações telefônicas e os encontros fortuitos”, Revista da Faculdade de Direito de Campos 6/7, 413-456.

Amaral, A. (1998): Estudo sobre quedas vocálicas e desestruturações silábicas no português de Lisboa. Tese de mestrado. Universidade de Lisboa.

Amaral, R. et al. (2007): "A prototype system for selective dissemination of broadcast news in European Portuguese", EURASIP Journal on Advances in Signal Processing 2007, ID 37507.

http://www.hindawi.com/GetArticle.aspx?doi=10.1155/2007/37507

Avila, R. (1999): "Difusión internacional del español por radio, televisión y prensa", in J. Padilla \& M. Déniz (orgs.): Actas do XI Congresso Internacional da ALFAL. Las Palmas: Universidad, 1265-1271.

BAAL - British Association for Applied Linguistics (2006): Recommendations on Good Practice in Applied Linguistics.

http://www.baal.org.uk/about_goodpractice_full.pdf 
Bacelar do Nascimento, M. F. et al. (1987): Português fundamental: métodos e documentos. Lisboa: INIC.

Bacelar do Nascimento, M. F. (2003): "Quelques considérations sur la constitution et l'exploitation d'un corpus de portugais parlé", in A. Scarano (ed.): Macrosyntaxe et pragmatique: l' analyse de la langue orale. Roma: Bulzoni, 295-302.

Bacelar do Nascimento, M. F. et al. (2005): "The Portuguese corpus", in E. Cresti \& M. Moneglia (eds.): C-ORAL-ROM: integrated reference corpora for spoken Romance languages. Amsterdam / Philadelphia: John Benjamins, 163-207.

Barkhuysen, P. et al. (2005): "Predicting end of utterance in multimodal and unimodal conditions", in I. Trancoso et al. (orgs.): Proceedings of Interspeech 2005 (Lisboa), 2417-2420.

Beskow, J. et al. (2006): "Visual correlates to prominence in several expressive modes", in Proceedings of Interspeech 2006 (Pittsburg), 1272-1275. http://www.speech.kth.se/prod/publications/files/1283.pdf

Blanche-Benveniste, C. \& C. Jeanjean (1987): Le français parlé. Paris: INALF/CNRS.

Boersma, P. \& D. Weenik (2007): Praat, versão 4.6.02. http://www.fon.hum. uva.nl/praat/

Campbell, N. (2002a): "Recording and storing of speech data", in P. Austin et al. (eds.): Proceedings of the International Workshop on Resources and Tools in Field Linguistics (Las Palmas), 6.1-6.3.

Campbell, N. (2002b): "Recording techniques for capturing natural every-day speech", in Proceedings of LREC II (Las Palmas), 2029-2032.

Campbell, N. (2004): "Speech \& expression: the value of a longitudinal corpus”, in M. T. Lino et al. (eds.): Proceedings of LREC IV (Lisboa), 183-186.

Campbell, N. (2005): "Getting to the heart of the matter: speech as expression of affect rather than just text or language", Language Resources $\varepsilon$ Evaluation 39, 1, 109-118.

Casey, M. \& B. Gordon (2007): Sound directions: best practices for audio preservation. http://www.dlib.indiana.edu/projects/sounddirections/best practices2007/

Castilho, A. \& D. Preti (eds.) (1987): A linguagem falada culta na cidade de São Paulo. São Paulo: FAPESP.

CDP - Digital Audio Working Group (2005): Digital audio best practices, versão 2.0. http://www.cdpheritage.org/digital/audio/documents/cdpdabp_1-2.pdf

Coates, J. \& J. Thornborrow (1999): "Myths, lies and audiotapes: Some thoughts on data transcripts", Discourse \& Society 10, 594-597.

Cresti, E. \& M. Moneglia (eds.) (2005): C-ORAL-ROM: integrated reference corpora for spoken Romance languages. Amsterdam / Philadelphia: John Benjamins. 
Duranti, A. (1997): Linguistic Anthropology. Cambridge: Cambridge University Press.

Farrar, S. et al. (2006): "Transcription and annotation of primary data", in Proceedings of 2006 E-MELD Workshop (Lansing).

http://www.emeld.org/workshop/2006/wg/wg2-report.pdf

Ford, C. (2004): "Contingency and units in interaction". Discourse Studies 6, $1,27-52$.

Freitas, T. \& F. Santos (2008): "CORP-ORAL: Spontaneous Speech Corpus for European Portuguese", in Proceedings of LREC VI (Marraquesh). http://www.lrec-conf.org/proceedings/lrec2008/

Hellwig, B. \& D. van Uytvanck (2007a): Manual do EUDICO Linguistic Annotator (ELAN), versão 3.3.0. http://www.lat-mpi.eu/tools/elan/

Hellwig, B. \& D. van Uytvanck (2007b): Manual do IMDI Editor, versão 3.2. http://www.lat-mpi.eu/tools/imdi/editor/

IMDI (2003): IMDI Metadata Elements for Session Descriptions. MPI Nijmegen. http://www.mpi.nl/IMDI/documents/Proposals/IMDI_MetaData_3.0.4.pdf

Local, J. \& G. Walker (2005): "Methodological imperatives for investigating the phonetic organization and phonological structures of spontaneous speech", Phonetica 52, 120-130.

Luke, K. \& T. Pavlidou (eds.) (2002): Telephone calls: unity and diversity in conversational structure across languages and cultures. Amsterdam / Philadelphia: John Benjamins.

Marquilhas, R. (2004): "Traços distintivos, góticos e electrónicos", in R. Álvarez \& A. Santamarina (eds.): (Dis)cursos da escrita. Estudos de filoloxía galega ofrecidos en memoria de Fernando R. Tato Plaza. A Coruña: Fundación Pedro Barrié de la Maza, 475-489.

Martin, P. (2004): "WinPitch Corpus: a text to speech alignment tool for multimodal corpora", in M. T. Lino et al. (eds.): Proceedings of LREC IV (Lisboa), 537-540.

Mateus, H. M. \& F. Bacelar do Nascimento (eds.) (2005): A lingua portuguesa em mudança. Lisboa: Caminho.

Manta, M. et al. (2006): Manual do Transcriber, versão 1.5.2. http://trans.sour ceforge.net/en/usermanUS.php

Moneglia, M. et al. (2005): "Evaluation of consensus on the annotation of terminal and non-terminal prosodic breaks in the C-ORAL-ROM corpus", in E. Cresti \& M. Moneglia (eds.): C-ORAL-ROM: integrated reference corpora for spoken Romance languages. Amsterdam / Philadelphia: John Benjamins, 257-276.

Ochs, E. (1979): "Transcription as theory", in E. Ochs \& B. Schiefflin (eds.): Developmental pragmatics. New York: Academic Press, 43-72. 
Plichta, B. (2002): "Best practices in the acquisition, processing, and analysis of acoustic speech signals", U. Penn Working Papers in Linguistics 8.3. http://www.historicalvoices.org/flint/extras/Audio-technology.pdf

Ramilo, M. C. \& T. Freitas (2002a): "A linguística e a linguagem dos media em Portugal: descrição do projecto REDIP”, in V. Corrales (ed.): Actas do XIII Congresso Internacional da ALFAL (San José).

Ramilo, M. C. \& T. Freitas (2002b): "Transcrição ortográfica de textos orais: problemas e perspectivas", in J. Fonseca et al. (eds.): Actas do Encontro Comemorativo dos 25 Anos do Centro de Linguística da Universidade do Porto. Vol. 2. Porto: CLUP, 55-67.

Reis, A. (2004): A complexidade interacional na central de reservas de uma companbia aérea. Enquadres, alinhamentos e seqüências conversacionais em um contexto institucional. Tese de doutoramento. Pontifícia Universidade Católica do Rio de Janeiro.

Rose, P. (2002): Forensic speaker identification. Londres: Taylor \& Francis.

Selting, M. (2000): "The construction of units in conversational talk", Language in Society 29, 477-517.

van Son, R. J. J. H. (2002): "Can standard analysis tools be used on decompressed speech?”. Comunicação apresentada no encontro COCOSDA2002, Denver.

Shriberg, E. (2005): "Spontaneous speech: How people really talk and why engineers should care", in I. Trancoso et al. (orgs.): Proceedings of Interspeech 2005 (Lisboa), 1781-1784.

http://www.speech.sri.com/papers/eurospeech2005-shriberg-keyno te.pdf

Shuy, R. (1993): "Risk, deception, confidentiality and informed consent", recensão crítica de D. Larmouth et al. (1992): Legal and ethical issues in surreptitious recording, American Speech 68, 103-106.

Schuurman, I. et al. (2004): "Linguistic annotation of the Spoken Dutch Corpus: If we had to do it all over again", in M. T. Lino et al. (eds.): Proceedings of LREC IV (Lisboa), 57-60.

Walker, G. (2004): The phonetic design of turn endings, beginnings, and continuations in conversation. PhD Diss. Univ. of York.

Zimmermann, R. (2004): "More pixels and samples: High resolution media streaming”. Comunicação apresentada na conferência Techs in Paradise (TIP 2004), Mānoa. 